\title{
Reduplication, Fusion, Inflexion-The Phonetic Proof of Moe Culture in Modern Chinese Language
}

\author{
Xiaotong Zhuang \\ Beijing Normal University, Beijing, China \\ Daxin Nie \\ Beijing Normal University, Beijing, China
}

\begin{abstract}
The present paper takes the popular language expressions in Chinese relating to the Moe Culture after its introduction from Japanese as the research object, aiming to analyze the important role of phonetic adjustment in enhancing the effect of Moe culture from the perspective of linguistics. It points out that reduplication, fusion and inflexion may enhance the effect of Moe culture through three specific mechanisms. The conclusion of the present study provides an angle and facts for clarifying the contact between Moe Culture and Chinese language under the development of modern society.
\end{abstract}

Index Terms - Chinese language, cross-culture, phonetic feature, Moe

\section{INTRODUCTION}

From the 1980s, Cute culture in Japan had an important influence throughout Asia and even the whole world. Recently, Cute culture, with the expansion of Japanese animation, has gradually generated a sub-branch named Moe culture. The word Moe (萌元) was first used to refer to the strong affection towards young and lovely girls in Japanese anime and then extended to all attractive young boys and girls afterwards with analogy to the feeling of affection towards any subjects. Yomota (2006) gave a brief account of the meaning development towards the word Moe when discussing Japan's Cute culture. He believes that the word Moe "originally means budding, but recently in the world of $o t a k u$ (御宅), who focuses on animation and games, the term has been used to express a deep attachment to a particular character or the elements of a person's body (such as uniforms, eyes, kansai dialect, etc.)"1(p.154). Moe has been popular since its appearance in year 2003, and was "nominated as Japan's first trendy phrase in year 2004 and 2005" 2 (Jiang, 2014, p.76). Then it developed the Moe culture, which defined by Wang (2012) as "people's uncontrollable deep love for all lovely things" ${ }^{3}$ (p.195).

In addition to the Cute culture and the unique animation environment, which has long been popular in Japan, the reason why Moe culture prevails not only because it meets the regression psychological needs of the mass, but it also adjusts people's tense and improves their rigid routine. Since young people have a fast-paced, stressful and rigid life, coupled with limited resources and frequent disasters, they are often living in a tense and anxious state of working condition. Those who live in a society similar generally have the psychological performance of regression. "The youth want to be able to stay at 19 and no longer to grow up, and if they have to grow up, they don't want to be married"4 (Wang, 2012, p.198). In fact, this is a decadent and cloistral tendency. The emergence of Moe culture has become a kind of modifier for mental and psychological needs in daily life, which fully alleviating the negative psychological tendency as well as showing strong relaxation and healing features. Therefore, cuteness focuses on the characteristics of things themselves, while Moe focuses more on people's subjective attitudes. If the feature of Moe has to be extracted, it can be summarized as adorable, adoring, novelty and youthful.

The social background and cultural characteristics needed for the transmission of the Moe culture mentioned above are slightly in line with those of China today, especially to the post-80s and post-90s generations. Once the Moe culture was introduced, therefore, it spread rapidly in China. Zhao (2016) described the spread of Moe force in the aspects of mascots, university publicity, commercial activities, political communication, national narrative, etc. He believed that Moe element is becoming more and more common and Moe force is a resource worthy of excavation and attention. In

${ }^{1}$ The original text is in Japanese,「本来は『芽が出る』という意味たが、最近のアニメやゲームを中心とする『おたく』の世界では、 特定のキャラクター、または制服や眼鏡、関西弁などキャラクターの一部分の要素に対し、深い思い入れを抱いて心が奪われる状態を 指す言葉として使われる」. The English is translated by the author.

2 The original text is in Chinese, “2004 年和 2005 年,“萌”当选为当年日本全国第一潮流用语”. The English is translated by the author.

${ }^{3}$ The original text is in Chinese, “人对一切可爱物事所持怀的情不自禁的深深爱恋”. The English is translated by the author.

${ }^{4}$ The original text is in Chinese, “年轻人都希望能滞留在 19 岁不再长大, 即使长大也不想成家”. The English is translated by the author. 
fact, as the carrier of social and culture, language could best reflect the social changes and cultural transmission. Moe culture has also brought many influences on different level of language. From the perspective of linguistics, one main influence of Moe culture on Chinese language, lying in the level of phonetical changes and expressions, could be explored.

In 2009, Japanese word Moe was introduced into China and substituted by Chinese word meng (萌). Followed by the popular trend of using meng as a morpheme, a series of new words constituted by meng have appeared, such as mai meng (卖萌, vi. pretending cute), meng wa (萌娃, n. cute baby), meng chong (萌宠, n. cute pet), meng meng da (萌萌 哒, adj. lit. cute cute PART., i.e. so cute). According to the Chinese Language Life Situation Report (2014), meng took the $7^{\text {th }}$ place according to the frequency of using among Chinese characters, and the word meng meng da was widely used in the second half of 2014, which well revealed its popularity.

Apart from the newly emerged meaning and expressions of meng in Chinese language, the phonetic adjustment is more direct and plays an equivalent important role on endowing with the effect of Moe culture, which could mainly be observed in reduplication, fusion and inflexion.

\section{REDUPLICATION}

Reduplication, being an important mean of morphology and syntax formation in any language, is the repeating of the same sound or syllable, which known as overlapping. Sun (2008) supposed, "Reduplication is the morphological method of word-formation, and in the process of which, a form is repeated, resulting in a new meaning"1 (p.3). In discussing the word-formation method, Ge (2001) pointed out that "the word is called reduplication when its phonetic form is made up with the overlap of a syllable"2 (p.109), such as goody-goody and hush-hush in English.

It is also a typical mean of using phonetic elements to enhance the effect of rhetoric and language expression. Wu (2016) summarized the rhetoric of reduplication as "a rhetorical text pattern in which two words of identical form, sound, and meaning are used closely together to achieve a particular linguistic effect"3 (p.275). Chen (2001) described the rhetorical effect of reduplication in this way: "(1) to increase the complexity of the language by the complexity of the sound; or (2) to harmonize the harmony of the tone by the sound" (p.169). There have been many reduplicationusing cases in Chinese to enhance the effect of language expression. For example, Qiqi Cancan Qiqi in Chinese might better reflect the feeling of miserable than no overlapping tone $Q i$ Can $Q i^{5}$.

With the introduction and influence of Moe Culture, reduplication, as a traditional lexical, syntactic and rhetorical mean, has been gradually borrowed to reveal and emphasize the feeling of cuteness more than just reach the purpose of indicating plural form of a noun or the degree of an adjective/verb, such as meng meng da, tutu (n. lit. rabbit rabbit, i.e. rabbit), $k u k u$ (vi. lit. cry cry, i.e. cry), etc. These new usages of reduplication, unnecessary and arbitrary, to reflect Moe Culture are obviously different from the traditional usages of necessary and fixed reduplication in catering to the habit of children's language expression. In addition to word-formation and rhetoric, reduplication is also a typical feature of children's language. Due to the limitation of language competence, children tend to simplify the complex pronunciation, such as choo-choo in English. Li (2003) pointed out that children's strategies of overlapping pronunciation co-exist with their using of simple syllabic structures. This similarly related strategy in adult's language would also make their language expression tend to those of children's, meeting the regression psychological needs of the mass, reducing their psychological stress, which fully reflects the immature of Moe culture. According to the different use of reduplication, the new reduplication well-represents the Moe culture can be divided into four categories.

\section{A. Replacing the Original Non-reduplication Disyllable Words by the Overlapping Form of One of the Morphemes}

In the evolution from ancient Chinese to modern Chinese, words have developed from monosyllabic to disyllabic. Except those formed by overlapped monosyllabic, most of disyllabic words are constructed by two different morphemes. However, under the influence of Moe culture, many traditional words used to be composed of two different morphemes are replaced by the overlapping certain one of the two morphemes.

\footnotetext{
${ }^{1}$ The original text is in Chinese, “重叠是一种形态构词手段,在重叠过程中, 一个形态得到重复,从而产生出一个新的意义”. The English is translated by the author.

${ }^{2}$ The original text is in Chinese, “词的语音形式是由音节重叠而成的叫做重叠式”. The English is translated by the author.

3 The original text is in Chinese,““将形、音、义完全相同的两个字紧密相连地用在一起”以企及某种特定语言效果的修辞文本模式”. The English is translated by the author.

${ }^{4}$ The original text is in Chinese, “（一）借声音的繁复增进语感的繁复; 或（二）借声音的和谐张大语调的和谐”. The English is translated by the author.

${ }^{5}$ Qiqi Cancan Qiqi: 凄凄惨惨戚戚, lit. means “so damp, so dank, so dead”, from the Song Lyrics Sheng Sheng Man, by Li Qingzhao, a famous female poet in Song dynasty.
} 
TABLE 1

EXAMPLES OF OVERLAPPING ONE OF THE MORPHEMES OF ORIGINAL NON-REDUPLICATION DISYLLABLE WORDS

\begin{tabular}{|c|c|c|c|c|}
\hline $\begin{array}{c}\text { English } \\
\text { Meaning }\end{array}$ & $\begin{array}{l}\text { Original } \\
\text { Expression }\end{array}$ & $\begin{array}{l}\text { Overlapping } \\
\text { Expression }\end{array}$ & $\begin{array}{l}\text { Literal Meaning of } \\
\text { New Word }\end{array}$ & Example \\
\hline thing & $\begin{array}{l}\text { dongxi } \\
\text { 东西 }\end{array}$ & $\begin{array}{l}\text { dongdong } \\
\text { 东东 }\end{array}$ & east + east & $\begin{array}{l}\text { Bie Chi Zhe Zhong Dongdong. (别吃这种东东, i.e. Don't } \\
\text { eat this kind of thing.) }\end{array}$ \\
\hline rabbit & $\begin{array}{l}\text { tuzi } \\
\text { 兔子 }\end{array}$ & $\begin{array}{l}\text { tutu } \\
\text { 兔兔 }\end{array}$ & rabbit + rabbit & Wo You Tutu. (我有兔兔, i.e. I have a rabbit.) \\
\hline fist & $\begin{array}{l}\text { quantou } \\
\text { 拳头 }\end{array}$ & $\begin{array}{l}\text { quanquan } \\
\text { 拳拳 }\end{array}$ & fist + fist & $\begin{array}{l}\text { Wo Yao Na Xiao Quanquan Chui Nide Xiongkou! (我 } \\
\text { 要拿小拳拳捶你的胸口, i.e. I will punch your chest with } \\
\text { my fist!) }\end{array}$ \\
\hline beautiful & $\begin{array}{l}\text { piaoliang } \\
\text { 漂亮 }\end{array}$ & $\begin{array}{l}\text { piaopiao } \\
\text { 漂漂 }\end{array}$ & beautiful + beautiful & $\begin{array}{l}\text { Wo de Yifu Tai Piaopiao la!（我的衣服太漂漂啦, i.e. } \\
\text { My clothes is so beautiful.） }\end{array}$ \\
\hline
\end{tabular}

The first three nouns usages and the last adjective usage all overlapped the first morpheme of the original word. The reasons include the following aspects.

(1) Only using the first morpheme could not accurately express the meaning of the word. When dong (东) is used independently, it is a positional word. Only when it is used together with the light-tone word $x i$ (西) can the meaning of “thing” be expressed. Piao (漂) is a non-word morpheme which could not be used independently. When $t u$ (兔) is used independently, it is a generic term for table categories, which could not match the meaning above. Quan (拳) could not be independently used with the word xiao (小). The most simple and effective way to express the original meaning in a novel way is overlapping.

(2) Compared with the second morpheme, the meaning of the first morpheme is more abundant. $Z i$ (子) and tou (头) are suffixes and do not have rich meaning. $X i$ is a morpheme with neutral tone, which was pronounced in a short time and contained less meaning. The semantics of the word piaoliang is also mainly borne by the pre-morpheme. Therefore, all the above cases overlapped the pre-morpheme.

(3) Overlapping coinage can give a new meaning to the word which fully reflects the immature of Moe culture. All of the above cases are taken from adult speech, which is not difficult for people to get the feeling of cuteness from them, as the using of reduplication being imitated is one common phenomenon in early period of childhood language.

\section{B. Overlapping Monosyllabic Words}

Although disyllabic words are the absolutely dominant in modern Chinese, there are still a great amount of monosyllabic words which exist and are used independently. In considering the appearance of Moe culture, some monosyllabic words could be used after overlapping, which was grammatically illegal and restricted in old days.

TABLE 2

EXAMPLES OF OVERLAPPING MONOSYLLABIC WORDS

\begin{tabular}{|c|c|c|c|l|}
\hline $\begin{array}{c}\text { English } \\
\text { Meaning }\end{array}$ & $\begin{array}{c}\text { Original } \\
\text { Expression }\end{array}$ & $\begin{array}{c}\text { Overlapping } \\
\text { Expression }\end{array}$ & $\begin{array}{c}\text { Literal Meaning of } \\
\text { New Word }\end{array}$ & Example \\
\hline meal & fan 饭 & fanfan 饭饭 & meal + meal & Chi Fanfan (吃饭饭, i.e. having meal.) \\
\hline pot & guo 锅 & $\begin{array}{c}\text { guoguo } \\
\text { 锅锅 }\end{array}$ & $\begin{array}{c}\text { pot + pot } \\
\text { 哭哭 }\end{array}$ & $\begin{array}{c}\text { Ba Wo de Guoguo Song Lai Ba(把我的锅锅送来吧, i.e. Get } \\
\text { my pan over here.) }\end{array}$ \\
\hline cry & ku 哭 & $\begin{array}{c}\text { chuichui } \\
\text { 吹吹 }\end{array}$ & Wow + blow & $\begin{array}{l}\text { Ba Ta Jian Qilai Chuichui! (把它捡起来吹吹, i.e. Pick it up } \\
\text { and blew it clean.) }\end{array}$ \\
\hline blow & chui 吹 & \multicolumn{2}{|c|}{} \\
\hline
\end{tabular}

In the first two noun cases, fanfan derived from fan (饭, n. rice/meal) and guoguo from guo (锅, n. pot). In the following two verbal usages, $k u$ (哭, v. cry) already accurately express the meaning, but in order to get people's attention and sympathy, the expression used the overlapping form kuku. Similarly, chui (吹, v. blow) is the most concise, effective and accurate expression, but in order to reflect the cuteness of the expression, the overlapping form chui took the place.

Comparing the overlapping forms in the above cases with the original form, it is clear to judge the connotative meaning of spoiled. There are two reasons: one is approaching and imitating the overlapping forms of children's language, which makes the language expression naive, and the other is to extend into disyllabic words by increasing the length of syllables and lengthening the rhythm of language, through which a more delicate emotional expression would be achieved. In short, by imitating the expression of children's language, people overlap monosyllabic words, increasing the semantic content and emotional infection, to express the cuteness.

\section{Replacing the Original Non-reduplication Form with Reduplicated Words}

In addition to the processing on the basis of existing words or morphemes, there lies a phenomenon of replacing the original non-reduplicative forms with overlapping words. 
In Chinese, the word bao (宝) has two main meanings, one of which means respect and love, while the other means treasure. The former semantic item is often used to express the love for children in the term baobao (宝宝, n. baby). According to the influence of Moe culture, the object baobao is the replacing expression of wo (pron. 我, myself). As an adult, the using of replacing indicates the coquetry behavior of the speaker. As the Bao has the meaning of treasure, some Chinese words containing bao are often related to money and property. Under the expansion of the effect of Moe culture, people create baobao juntuan (宝宝军团, n. lit. the baby's army) to refer to a large number of online financial products. This expression is used instead of financial products because, on the one hand, it can vividly reflect the common morpheme bao, and on the other hand, it can highlight the feeling of loveliness.

Zhuzhu nühai (猪猪女孩) in modern Chinese refers to the girls who look silly but have optimistic attitude of life ${ }^{1}$. Compared with silly and optimistic girls, zhuzhu Nühai exhibits a more concise and lovely implication on the contrary, which also manifest the respect and love for this group of people. It can be drawn from this case that reduplication conveys the characteristics of Moe culture by making the language expression more vivid.

\section{D. “ $X X D a$ ” Series of the Overlapping}

With the frequent use of $d a$ (哒), a series of $X X D a$ formed by the combination of adjective reduplication and $d a$ becomes more and more abundant. New expressions under the influence of Moe culture such as mengmengda, zuizuida (醉醉哒) and meimeida (美美哒) have emerged. This usage converts the ABB pattern into AAB pattern, which was the most common form of adjective reduplication in traditional Chinese morphology structure. The new AAB pattern is mainly used to describe the emotion or the state of organism, and then it has gradually expanded into inanimate objects.

The factors of $d a$ will be detailed analyzed in the following pages. The function of the pre-overlapping form is the same as the examples mentioned above, that is using the childlike tone to enhance the expression of the lovely elements in the Moe culture. On the other hand, the use of overlapping forms of adjectives can also enhance descriptiveness and vividness of the expression, enhancing the expression of a certain feeling and emotions, such as affection.

\section{FUSION}

Fusion is a combination of two syllables. Chao (1968) defined it as "fusion is the telescoping of two different syllables, often representing separate morphemes, into one"(p.80). There are a lot of symphonic phenomena in the language using. Ginormous in English comes from the combination of giant and enormous, while zhu (诸) in ancient Chinese derived from the fusion of Zhi yü (之于, lit. it from), i.e. the initial of the first syllable and the final of the second. Under the influence of the Moe culture, the phonetic fusion is also used to transform the vocabulary and phonetic patterns in creating a lovely feeling of expression. New fusion form is not widely used and only used to embody the characteristics of Moe culture.

The most prominent phenomenon of fusion arising from the influence of Moe culture is da (哒), such as mengmengda and zuizuida. The Modern Chinese Dictionary (The seventh edition) pointed out that 哒 is same as 嗒, which means "to describe the sound of horseshoe, machine gun, etc." ${ }^{2}(2018$, p.231). This explanation is obviously different from the one in the present paper that influenced by Moe culture. Da, used in certain dialects as well, is only considered as an auxiliary word, which is also obviously different from the current usage. Wu (2018) has investigated the sources of the current $d a$ and states the viewpoints of consonant speech, transliteration and dialect influence. On considering the usage and universality, it is reasonable to take for granted that the viewpoint of fusion is more realistic.

According to the principle of fusion, $d a$ is the combination of structural auxiliary $d e$ (的) and modal particle $a$ (啊). The $X X D a$ series combined with the overlapping of the monosyllabic adjective and $d a$ can be transformed into the form of XX De a. For example, mengmengda is the form of mengmeng de a, other expressions like meimeida and zuizuida both in accordance with this principle. Although $d a$ appeared in the phonetic stage is a combination of $d e$ and $a$, when solidified and determined, it is no longer confined to the use of the combination of $d e$ and $a$, but descended an independent modal word for certain meanings, such as shi da (是哒, lit. be da, i.e. yes), dui da (对哒, lit. right da, i.e. correct) and hao da (好哒, lit. good da, i.e. alright), which is roughly the same as de. Furthermore, instead of monosyllabic replies or overlapping monosyllabic adjectives, the segment before $d a$ has some more complex patterns, such as Ni Shi Wo Da (你是我哒, lit. you be my da, i.e. you are mine)". Although da in the above could be replaced by $a$ or $d e a$, the acoustic sensation of $d a$ is brighter and shorter, which better reflects the joyous characteristics of Moe culture. In addition, Zhang (2011) pointed out that "when babies are anxious or uncomfortable, they often emit ' $\mathrm{i}$ ' and 'e', while in the pleasant state, the sounds of 'a', 'o', 'u' are more often emitted"3 (p.40). Therefore, the fusion form $d a$ could reduce objectionable pronunciation and fully express the feeling of pleasure.

The expression in Taiwan Mandarin is another unique sample. In this dialect, there are lots of fusion phenomena in speech flow and the pronunciation of itself gives an acoustic sense of tender and soft, which drove the mass in mainland

\footnotetext{
${ }^{1}$ Zhu (猪, pig) in Chinese is frequently embedded with items like negative and clumsy.

2 The original text is in Chinese, “形容马蹄、机枪等的声音”. The English is translated by the author.

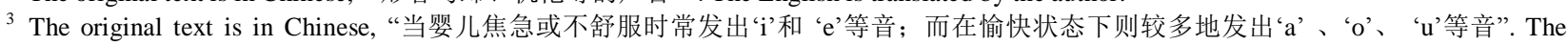
English is translated by the author.
} 
China to imitate the phenomenon of conjunction in Taiwan Mandarin to express the Moe. Taking pengyou (n. 朋友, friend) for example, the pronunciation of this disyllable is combined into the sound of piao that homophonic coincident to the word piao (n. 票, ticket). Therefore, people imitate this fusion phenomenon and turn nanpengyou (n. 男朋友, boyfriend) into nanpiao (男票, lit. male ticket) and nüpengyou (n. 女朋友, girlfriend) into nüpiao (女票, lit. female ticket). It conforms to both the disyllabic feature of modern Chinese and the adorable feature of Moe culture. Other similar changes are detailed in the Fig. 3 below.

TABLE 3

EXAMPLES OF PHONETIC FUSION IN STANDARD CHINESE

\begin{tabular}{|c|c|c|c|c|}
\hline $\begin{array}{c}\text { English } \\
\text { Meaning }\end{array}$ & $\begin{array}{c}\text { Mandarin } \\
\text { Expression }\end{array}$ & $\begin{array}{c}\text { Fusion } \\
\text { Expression }\end{array}$ & $\begin{array}{c}\text { Literal Meaning of } \\
\text { New Word }\end{array}$ & Example \\
\hline to know & zhidao 知道 & zao 造 & to make & Ni Zao Ma (你造吗? i.e. Do you know?) \\
\hline to like & xihuan 喜欢 & xuan 宣 & announce & Wuan Ni (我宣你 i.e. I like you.) \\
\hline this kind & zheyang 这样 & jiang 酱 & sauce & Biao jiang zi (表酱紫 i.e. Don't be like this.) \\
\hline do not & buyao 不要 & biao 表 & watch(n.) & \\
\hline
\end{tabular}

Among these examples, the particular one is the expression jiangzi, in addition to using the fusion to convert zheyang into a jiang, the Chinese word $z i$ (子, particle) is also replaced by the homophonic form zi (紫, purple), the colored expression of which makes people feel feminine, tender and cutie. Although in actual language communication and certain age range, these usages do not cause misunderstandings, the fusion shown in the above examples are only a temporary simple deduction in certain circumstances, which would not leading to an increase of a new semantic item to the original Chinese word.

To sum up, different from the traditional Chinese phonetic combination or fusion, the fusion arising from the influence of Moe culture imitate the traditional Chinese phonetic combination to express the characteristics of the Moe culture. There are three ways to achieve the objectives. Firstly, this approach speeds up the language rhythm and enhances the light and cheerfulness of the language through fusion. Secondly, this approach breaks traditional patterns and builds an alternative form of language expression. Lastly, it imitates the rhetorical mode of childrenese. Dysarthria is considered to be one of the important obstacles in children's language, performing in the omission of the beginning or the ending consonants. Instead of treating it as a barrier, this article prefers to treat it as a special child pronunciation strategy. The fusion usages arising from the influence of Moe culture exactly imitates this special rhetorical mode to enhance the expression of Moe culture.

\section{INFLECTION}

Inflection is the phonetic alternation of the original pronunciation. In Chinese, it is often a change of initial consonant, simple or compound vowel or the tone. The traditional inflection phenomenon is mainly used in three cases. The first lies in morphologic formation. Words with or without retroflexed- $r$ as the final end varies in the comparison between verb gai (盖, to cover) and its noun form gar (盖儿, the cover) through the retroflection. The second is the pronunciation variations in the speech flow resulting in assimilation, dissimilation, weakening, shedding, etc. In word mianbao (面包, bread), the final $-n$ in the first syllable will be assimilated to $-m$ due to the bilabial plosive initial $b$ - in the second syllable. The third one is diachronic phonetic change, which mainly refers to the changes of the phonetic system over times, such as the Grimm's law. Different from the traditional ones, the inflection influenced by Moe culture is neither a phenomenon in the process of diachronic development, nor a phenomenon of word formation or language flow. It is used for the purpose of expressing the trait of Moe. People, under which, alter the original pronunciation of words by a homophonic word. The differences between the traditional phonetic alteration phenomenon and the new inflection phenomenon are in the following aspects.

Firstly, expression forms are different. Traditional inflection phenomenon is only shown in the pronunciation and the writing form remains the same. The new inflection phenomenon of the phonetic change, however, is directly reflected in the changing of writing form.

Secondly, the initiatives are different. The traditional inflection phenomena are not deliberate, while the new ones are deliberate changes to reflect the characteristics of Moe culture.

Thirdly, the nature and status of the two are different. The traditional inflection phenomenon is a fundamental change with universality, while the emerging one is only used in certain communities and its existence cannot replace the original pronunciation form.

According to the different causes of the variation, it can be divided into three variants, caused by foreign language, Chinese dialect and standard mandarin homophone respectively.

\section{A. Changing the Transliteration of Foreign Language}

Transliteration is one of the most important ways to introduce foreign words into Chinese. Unlike traditional transliteration, the emerging usages are not always for the sake of accurate translation, but a new and unique way to retranslate the existing borrowed expression in order to be Moe. 
TABLE 4

EXAMPLES OF CHANGING THE TRANSLITERATION OF FOREIGN LANGUAGE

\begin{tabular}{|c|c|c|c|}
\hline English Expression & Traditional Transliteration & Re-translate Expression & Literal Meaning of New Word \\
\hline party & juhui 聚会 & pati 跃体 & grovel body \\
\hline $\begin{array}{c}\text { too young } \\
\text { too simple }\end{array}$ & $\begin{array}{c}\text { hen sha hen tianzhen 很俊 } \\
\text { 很天真 }\end{array}$ & $\begin{array}{c}\text { tuyangtusenpo } \\
\text { 图样图森破 }\end{array}$ & chart sample chart forest broken \\
\hline go die & si 死 & goudai 狗带 & dog chain \\
\hline idol & ouxiang 偶像 & aidou 爱豆 & cute bean \\
\hline
\end{tabular}

The word pati is a direct transliteration of the English word party. Instead of using the local word juhui, pati makes people feel more informal and leisure through the Chinese character pa. Goudai is the English expression go die. This expression will make people feel lovely because in Chinese, people can connect goudai with the cute dog. Aidou is actually the English word idol. A portray of person with round, little, rolling, not strict will come more direct and cartoonish in front of the vision. This new and distinctive way of translation is aiming to break the traditional expressions and create a new and adorable feeling, just as the Chinese words like gou and dou will also enhance the loveliness of these special transliteration forms with the corresponding things.

In addition to letting people associate adorable things or actions through homophonic, changing the transliteration of foreign language can also help people harvest a novelty and cute feeling through an illusion of non-standard pronunciation. The aforementioned expressions adopt the approach of Chinese homophonic to re-translate the English expressions, just like the pronunciation of a person who is new to English. This attempt to get the pronunciation right through endeavor pleasures the masses and motivates the emergence of affection. The phrase tuyangtusenpo is the most obvious representative.

\section{B. Using the Pronunciation of Dialects to Change the Pronunciation of the Words}

Differences between the pronunciation of Chinese dialects and standard mandarin provide favorable variants for the change of pronunciation. People either borrow different pronunciation from certain dialects, or pick up those errors in the failure of correcting the pronunciation of words in the process of learning standard mandarin by creating a lovely feeling and atmosphere of language more than a mock.

In the phonetic system of standard mandarin, there is a distinctive difference between the labio-dental $f$ - and soft palatal $h$-. However, it makes no difference between these two phonemes in Hokkien dialect, which clearly distinguish those people during the misuse of daily communication. This kind of misuse is often regarded as comedic and cherubic, which leads to the imitation of those standard mandarin speakers. For example, the word fang (方, square) is the incorrect pronunciation of huang (慌, adj. panic). The Hokkienese change the initial $h$ - in huang, which not exist in such dialect phonetic system, into $f$ - in fang and use the word 方 to represent. This pronunciation alternation enhances the novelty and cuteness of language expression. Meanwhile, since fang in Chinese means a quadrilateral shape, it is always used with a square face emoji to express the internal panic in social media platforms communication and the feeling of loveliness becomes more and more prominent. The word huiji (灰机, lit. gray machine) is actually feiji (飞机, n. plane), in which the sound $h$-is also replaced by $f$-. The change of the pronunciation is reflected by the change of Chinese word from 飞 (v. fly) to 灰 (adj. gray), which enhances the feeling of cuteness.

Another commonly misused situation derived from dialects to standard Mandarin is the confusion between final $-n$ and $-\eta$. For example, penyou (盆友, lit. basin friend) is actually pengyou (朋友 n. i.e. friend), in which people substitute the pronunciation /əy/ by /ən/ and use the Chinese word 盆 instead. The dialectal feature not only influenced mandarin, but also to English, as in the phrase Sing Song to Sin Son by Hokkienese. According to the laws of inirreversible solidarity, the acquisition of a phoneme mainly depends on the distribution of the phoneme in the world. The widely distributed phonemes could be learned earlier while the unique phonemes later. The distribution of the consonants articulated near the bank of the vocal cavity (such as $-\eta$ ) is less than those articulated near the front of the vocal cavity ( such as $-n$ ), so the former is more difficult to pronounce and was later learned. Under the influence of Moe culture, the masses use the pronunciation of dialects to change $-\eta$ to $-n$, and put up a false front of a younger age tend and regression, which enhance the perception of likability.

Some southern dialects in modern Chinese have no difference between flat tongue sound and cacuminal sound, which is similar to the acquisition of child. According to Wen (2008), the hardest initials for child to master are $z-, c-, s-$ $z h-, c h$ - and $s h$-. So dexterously utilizing these confused phenomena could reminiscent of the scene of learning phonetic transcription, embodying the cuteness of Moe. The word saonian (骚年, lit. coquettish year ) is the variant form of shaonian (少年, n. teenager). People change the retroflexe sh-into the blade-alveolar s- and use the Chinese word 骚 to reflect this change. Similarly, the word seng (僧, lit. monk) is sheng (生, n. student). The word zishi (姿势, posture) is the variant form of zhishi (知识, n. knowledge), in which the pronunciation is the retroflex [s] instead of the bladealveolar [s]. The dull word zhishi can be replaced by the word zishi after inflection, producing a sense of droll and humorous.

In addition, influenced by pronunciations in different dialects, some other corresponding inflection phenomena have emerged in Mandarin. These inflection phenomena are manifested on the initials, finals and both. The examples can be 
organized into Fig.5. Although people in the dialect area express in this way, only when they are deliberately said by young people will they be considered as Moe culture. Saying by others will be generally considered to be non-standard .

TABLE 5

OTHER INFLECTIONS INFLUENCED BY DIALECTS

\begin{tabular}{|c|c|c|c|c|}
\hline English Meaning & Original Expression & Inflection Expression & Literal Meaning of New Word & Dialect Area \\
\hline brain & nao 脑 & lao 老 & old & Sichuan \\
\hline handsome guy & shuai ge 帅哥 & shuai guo 帅锅 & handsome + pot & Sichuan \\
\hline anxious & zhaoji 着急 & zhuoji 捉急 & catch + anxious & Jiangxi \\
\hline how & zenme 怎么 & zhongme 肿么 & swollen + PART. \\
\hline
\end{tabular}

To sum up, people generally tend to borrow dialectal forms to change the more laborious pronunciation into a more labor-saving pronunciation. On the one hand, this change prompts to a parallel association and on the other hand, it puts up a false front of a younger age tend and regression, which all enhances the perception of likability.

\section{The Inflection Produced by Using the Homophonic Sounds}

In addition to the inflections produced by slightly changing the transliteration of foreign language and using the pronunciation of dialects, it can also change the pronunciation of the word to reach the achievement by using the homophonic sounds.

The first type of this inflection is to skillfully borrow homophonic sound and convert into words which are originally used to represent defenseless animals. For instance, the modal particle ya (呀, PART.) is homophonic accord with ya (鸭, n. duck) and only the tone is slightly different. The latter one will be used to replace the former one for the purpose of enhancing the expressiveness of words. Modern Chinese has lots of this kind of usages like chongya (冲鸭, lit. rush duck) and yao kaixin ya. Words whose pronunciation is homophonic accord with ji (鸡, n. chicken) will be converted to it. For example, the young people prefer to use chaoji (炒鸡, lit. fried chicken) instead of chaoji (超级, super). It is the same reason to replace liao (了, AUX.) by niao (乌, bird) and $m e$ (么, suffix) by ma (马, house). The specific usages are shown in Fig.6.

TABLE 6

INFLECTIONS BORROWING HOMOPHONIC TONES WITH THE WORD REPRESENTING DEFENSELESS ANIMALS

\begin{tabular}{|c|c|c|c|c|}
\hline $\begin{array}{c}\text { English } \\
\text { Meaning }\end{array}$ & $\begin{array}{c}\text { Original } \\
\text { Expression }\end{array}$ & $\begin{array}{c}\text { Homophonic } \\
\text { Expression }\end{array}$ & $\begin{array}{c}\text { Meaning of } \\
\text { New Word }\end{array}$ & Example \\
\hline PART. & ya 呀 & ya 鸭 & duck & Yao Kaixin ya. (要开心鸭. i.e. You have to be happy.) \\
\hline level & ji 级 & ji 鸡 & chicken & Chaoji (炒鸡, lit. fry chicken, i.e. super ) \\
\hline AUX. & liao 了 & niao 鸟 & bird & Shou bu niao (兽不鸟. i.e. could not stand) \\
\hline suffix & me 么 & ma 马 & horse & Shenma (神马, lit. god horse, i.e. what) \\
\hline
\end{tabular}

Using homophonic sound to convert words into those referring to animals could bring a sense of adorable because of the cuteness of the animals themselves and the regressive characteristic of language expression. According to Zhou (2001), animal vocabulary is one of the earliest lexical fields learned by Chinese children. Therefore, this transformation can make people tend to become younger and the sense of cuteness is realized.

Secondly, homophonic sounds are used to convert the words into other words which refer to things or images with adorable features. For example, a chubby image often includes a sense of innocence and loveliness, so people skillfully borrow the homophonic sound to convert the word pengyou (朋友, $\mathrm{n}$. friend) to pangyou (胖友, lit. fat friend), in which the pronunciation [ə⿹] becomes [ay]. Besides, since a thick scarf could make people feel warm and comfortable, the word weibo (微博, micro-blog) is replaced by the homophonic word weibo (围脖, scarf), in which the high-level tone became a rising tone in the first syllable.

In short, the use of the homophony in mandarin Chinese and converting words into other ones which have similar pronunciation but different written forms with the original ones can fully show the loveliness of the Moe culture.

According to the above, inflection also embodies the characteristics of Moe. It has three specific mechanisms. Firstly, it breaks the traditional way of language expression by changing the pronunciation of the words and makes the language become novel and young. Secondly, by making use of phonetic changes, we can simplify the laborious pronunciation and make abstract things concrete. This simplified method fully reflects the characteristics of low age and infantilization. Thirdly, this method correspond the change of pronunciation with the change of Chinese characters, so the original expression of words is transformed into the corresponding expression of words which are referred to lovely things, enhancing the sense of loveliness. In a word, people use the homophonic sound to embody Moe through the cuteness of the things and the regressive characteristic of language expression.

\section{CONCLUSION}

The present paper takes the popular language expressions in Chinese relating to the Moe Culture after its introduction from Japanese as the research object, analyzing the important role of phonetic adjustment in enhancing the effect of 
Moe culture from the perspective of linguistics. It points out that reduplication, fusion and inflexion may enhance the effect of Moe through three specific mechanisms. Firstly, it utilizes the regressive characteristic of language expression to approximate the expression to the infant. Secondly, it utilizes the change of rhythm to enhance the descriptiveness of the expression and emotion. Thirdly, it utilizes the homophonic sound to correlate the adorable objects.

In a word, the Moe culture which originally only appeared in cartoons spread its usage after intervened in Chinese, largely because people are changing from conservative to innovation. A few types of phenomena reflected in the language level: reduplication, fusion and inflexion are all the performances of communicative needs. Although the main applicable group is still young people, this trend is somehow gradually spreading to other age groups. Instead of refusing to accept or even openly criticizing it as before, these new ways of expression are getting more and more acceptance. This, in certain point of view, mirrors the changes of Chinese traditional values and ideology.

\section{ACKNOWLEDGEMENTS}

The present paper is sponsored by Municipal Social Science Fund of Beijing (No. 17YYC016) and National Social Science Fund of China (No. 17ZDA264).

\section{REFERENCES}

[1] Chao Yuenren. (1968). Language and symbolic systems. Cambridge: Cambridge University Press.

[2] Chen Wangdao. (2001). An introduction to rhetoric. Shanghai: Shanghai Education Publishing House.

[3] Ge Benyi. (2001). Modern Chinese lexicology. Jinan: Shandong People's Publishing House.

[4] Institute of Linguistics, CASS. (2016). Modern Chinese dictionary (7th edn.). Beijing: The Commercial Press.

[5] Jiang Feng. (2014). From Tokyo. Xi'an: Shaanxi People's Publishing House.

[6] Li Qingrong. (2002). Modern practical Chinese rhetoric. Beijing: Peking University Press.

[7] Li Yüming. (2003). Language learning and teaching. Beijing: Beijing Broadcasting Institute Press.

[8] Sun Jingtao. (2008). Research on overlapping word-formation in ancient Chinese. Shanghai: Shanghai Education Publishing House.

[9] Wang Yonghao. (2012). Know Japan. Shanghai: Fudan Press.

[10] Wu Jin. (2018). The origin of the Internet communication term Da. Study on Chinese 3, 182-186.

[11] Wu Liquan. (2016). Modern Chinese rhetoric (3rd edn.). Shanghai: Fudan Press.

[12] Yomota Inuhiko (ed.). (2006). The cute. Tokyo Metropolitan: Chikubukuro.

[13] Zhang Minghong. (2011). Language development and education for children aged 0-3. Shanghai: East China Normal University Press.

[14] Zhao Xinli. (2016). The force of Moe: the theory of Cute Culture's communication. Beijing: People's Daily Press.

[15] Zhou Guoguang, Wang Baohua. (2001). The research of children's sentence development and the theory of language acquisition. Beijing: Beijing Language and Culture University Press.

Xiaotong Zhuang is an M.A. at Beijing Normal University in the School of Chinese Language and Literature. She received a bachelor's degree in Beijing Normal University. Her research focuses on Modern Chinese.

Daxin Nie is a lecturer at Beijing Normal University in the School of Chinese Language and Literature. He received a Ph.D. in Peking University with a focus on Linguistics and Applied Linguistics. His research interests include language contact, Chinese philology and Cross-cultural Research. 